\title{
ANÁLISIS CRÍTICO DE LA LEGISLACIÓN COLOMBIANA FRENTE AL CONCEPTO DE PERSONA
}

Julieta Melo Correa*

Recibido: 05.07.2015

Aprobado: 08.08.2015

\section{RESUMEN}

El presente estudio trata acerca del concepto de "Persona", a partir de la revisión normativa de su tratamiento en la legislación colombiana, haciendo un análisis crítico de la misma, teniendo en cuenta la naturaleza del ser humano.

\section{ABSTRACT}

This study discusses the concept of "Person" as used in the Colombian law and makes a critical analysis of how the law uses such concept, given the nature of human beings.

\section{PALABRAS CLAVE}

Inicio de la vida - Status jurídico de la persona - Protección del nasciturus.

\section{KEY WORDS}

Beginning of life. Individual's status. Protection of the unborn child.

\section{INTRODUCCIÓN}

En el ámbito del Derecho de Familia en Colombia, don Andrés Bello no pudo prever en su Código Civil los grandes problemas jurídicos que se plantearían en la actualidad como consecuencia del desarrollo tecnológico, biológico, médico y científico. La velocidad con la que crecen las posibles y probables aplicaciones del saber científico han trastocado a nivel legal uno de los conceptos básicos de todo ordenamiento jurídico, como lo es el concepto legal de persona en el Có- digo Civil colombiano (Art. $33^{1}$ y $74^{2}$ ), específicamente en lo que hace mención al concepto de personalidad jurídica del nasciturus (Art. $90^{3}$ y 914) enmarcando su definición dentro de un ordenamiento jurídico mixto tales como en los países de China, Francia, Italia, Ni-

Abogada colombiana. Magister en Bioética por la Universidad Libre Internacional de las Américas.

1 Artículo 33 C.C. de Colombia.- La palabra persona, en su sentido general se aplica a la especie humana, sin distinción de sexo.

2 Artículo 74 C.C. de Colombia.- Son personas todos los individuos de la especie humana, cualquiera que sea su edad, sexo, estirpe o condición.

3 Artículo 90 C.C. de Colombia.- La existencia legal de toda persona principal al nacer, esto es, al separarse completamente de su madre. La criatura que muere en el vientre materno, o que perece antes de estar completamente separada de su madre, o que no haya sobrevivido a la separación un momento siquiera, se reputará no haber existido jamás.

4 Artículo 91 C.C. de Colombia.- La ley protege la vida del que está por nacer.

El juez, en consecuencia, tomará, a petición de cualquiera persona, o de oficio, las providencias que le parezcan convenientes para proteger la existencia del no nacido, siempre que crea que de algún modo peligra. 
caragua, Portugal, R. de Cabo Verde, Chile, quienes consideran que el nacimiento vivo determina la personalidad, pero se le otorgan al nasciturus algunos derechos en suspenso que garantizan su protección y el respeto de sus derechos fundamentales, quedando claro que en Colombia se niega rotundamente la personalidad del concebido.

No obstante que la Constitución Política ${ }^{5}$ y la jurisprudencia colombiana, brindan protección al nasciturus desde el momento de la concepción hasta el final de su existencia física, existe en el derecho colombiano grandes divergencias o contradicciones resultante de la interpretación sistemática de varios artículos legales correspondientes al Código Civil Colombiano, Código Penal, Constitución Política de 1991 y jurisprudencia de la Corte Constitucional y la misma Sentencia C-355 del 2006, con la cual se despenaliza el aborto en Colombia en tres situaciones específicas: 1).Cuando el embarazo constituya peligro para la salud o la vida de la mujer. 2).Cuando exista grave malformación del feto que haga inviable su vida. 3). Cuando el embarazo sea el resultado de una conducta debidamente denunciada, constitutiva de acceso carnal o acto sexual sin consentimiento (violación), abusivo, o de inseminación artificial o de transferencia de ovulo fecundado no consentida, o de incesto; lo anterior con el agravante para los jueces quienes deben fallar basados en la Constitución y la ley, no en convicciones religiosas, políticas, filosóficas. No fallar un caso de IVE, dará lugar a responsabilidad del Estado por falta de acción de sus funcionarios y el juez podrá ser sancionado penal y disciplinariamente según T-946/08, T-388/09; igual consideración se aplica para los médicos que se nieguen a practicar el aborto, pues no cuenta la objeción de conciencia.

Con la promulgación de la referida sentencia, se infiere claramente que no le reconoce el carácter de persona al nasciturus al colegirse en uno de sus apartes la protección de la vida en gestación y no el carácter de persona del nasciturus, utilizándose en dicha sentencia argumentos propios del utilitarista Peter Singer como: Solo es persona quien goza y es capaz de libertades, por lo tanto tiene derecho a la vida quien tiene autonomía y capacidad de concebir el futuro ${ }^{6}$, imponiendo la Corte su propia postura sin haber precisión legal, decidiendo sin consenso político, delimitando el alcance del legislador, desconociendo su propia jurisprudencia y la misma Constitución Política, olvidando que la función de la Corte Constitucional es vigilar que las normas no contradigan la Constitución.

Por lo tanto, no le corresponde definir el concepto de persona y sobre todo negarle la posibilidad al nasciturus de ser persona al ponderar derechos fundamentales en la mujer, estableciendo la Corte una diferencia entre él bebe in-útero y él bebe ex-útero, imponiendo una decisión desfavorable para el no nacido por el mero cambio de escenario que se traduce en un incremento absoluto de disponibilidad del embrión, quedando reducido a "mera estructura celular", - "cosa", llevando al nasciturus a un empobrecimiento del concepto sin precisión de lo que significa "PERSONA", sujeto a criterios utilitaristas y demonizados, quienes reconocen la dignidad solo a quien se muestre en condiciones de ejercer su autonomía, provocando una "dislocación" de los conceptos de ser humano y persona, dejando claro que "el nacimiento determina la personalidad", como si se tratara del "ser hombre" en vez de el "ser humano", desdibujándose con ello el concepto, despreciándose al ser humano como titular de derechos y deberes intrínsecos e inalienables, quedando los derechos del nasciturus sometidos al poder del Estado y del derecho positivo colombiano y quienes a la final, determinan quién es persona según soplen los vientos políticos, sin tenerse en cuenta argumentos razonables que involucren principios Bioéticos, conceptos y valores, compartidos por las distintas visiones omnicomprensivas presentes en una sociedad democrática, donde se tengan en cuenta la moral cristiana, una bioética con fundamentación

Constitución Política de Colombia, Art.11: El derecho a la vida es inviolable. No habrá pena de muerte.

Singer, Peter Albert David. Ética práctica. Cambridge Universiti Press, segunda edición, 1995, pgs.113, 117, 118, 121, $122,124,125$. 
personalista y no un consenso social de pocos, fundamentado en intereses particulares exclusivos de un grupo minoritario como resultado de un forcejeo político, lo que conduce al ordenamiento jurídico colombiano a ofrecer una arcaica y dual definición del concepto de persona, provocando los mayores riesgos de indefensión para el no nacido.

Lo anterior, pone de manifiesto la visible incongruencia de algunos juristas respecto al concepto de persona del nasciturus, no siendo compatible con los postulados de la Constitución Política de Colombia -considerada norma de normas-, el mismo preámbulo de la Declaración Universal de los Derechos Humanos de la ONU de 1948, el preámbulo del Pacto internacional de Derechos Civiles y Políticos de 1966, entre muchos otros.

Por tales razones y con fundamento en la Constitución Política de Colombia, el Código Civil, el Código Penal y algunas jurisprudencias colombianas, haré a continuación, en tres etapas, un análisis al respecto, en donde podrá evidenciarse la divergencia de conceptos jurídicos en Colombia, tratando el particular en el siguiente orden:

1.- Antecedentes jurídicos del concepto "persona".

2.- Aspecto normativo. Descripción y críticas, exponiendo razones suficientes para el replan- teamiento del concepto de "persona".

3.- Fundamentación

para atribuirle al nasciturus el carácter de persona desde la concepción.

4.- Conclusiones.

\section{ANTECEDENTES JURÍDICOS DEL CONCEPTO "PERSONA"}

El vocablo "persona" ha evolucionado desde un concepto atécnico a uno técnico-jurídico, vinculado a la capacidad patrimonial propia del Derecho Civil colombiano, hasta llegar al concepto valórico institucional de persona; es así como el concepto jurídico de persona se va forjando como un modo de argumentar comportamientos sociales -patrimoniales- de derechos susceptibles de generalización.

En la primera etapa se dio el concepto atécnico: "persona", viene del latín personae, este del etrusco "phersu" y este se deriva de "про́

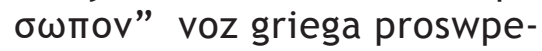
kon (prosopeion), que significa "máscara que cubría el rostro del actor o desempeñar un papel"; posteriormente, fue utilizada por los romanos $^{7}$; poco después, el término persona pasó a designar al propio actor enmascarado: "al personaje": en esta etapa, el término persona es utilizado como sinónimo de hombre, respondiendo a las condiciones de cultura, grupo social y político, con influencias de los hebreos (religión), griegos (filosofía) y romanos (leyes).

En los primeros siglos de la era cristiana, bajo el influjo de la filosofía, el término "persona" se refiere a la sustancia de la naturaleza intelectual; posteriormente, se refiere al ser humano considerado "sustancia individual de naturaleza racional", en la clásica definición de Anicio Manlio Torcuato Severino Boecio(480-524) en el tratado sobre La persona y las dos naturalezas contra Eutiques y Nestorio ${ }^{8}$; posteriormente, San Agustín, Santo Tomás, San Anselmo, hacen un contraste entre persona y sustancia; se van integrando elementos metafísicos, donde "persona" es identificada con "identidad personal" y con la "conciencia", se da la analogía entre lo teológico y lo antropológico generando definiciones más explicitas ("naturaleza y persona”, en Cristo). Frente al pensamiento griego, el judaísmo centra su atención en la historia más que en la naturaleza: el hombre deja de ser un elemento más de la naturaleza para convertirse en un ser distinto a los demás9.

En la segunda etapa, llamada técnico-jurídica, "persona" tiene una naturaleza funcional y padece de contingencia, pues el vocablo también fue usado jurídicamente como "sujeto legal", sin que ello denote a "persona" como sustancia sino más bien lo que designa el rol jurídico - for-

\footnotetext{
7 Orozco Delclos, Antonio. Fundamentos antropológicos de ética racional. Capítulo I: Que es la persona y cuál es su dignidad. En revista Cuadernos de Bioética, No13, primera edición, 1993, p. 40,41.

8 Compleston, Frederick .Historia de la filosofia.9 volumenes.Barcelona,editorial Ariel S.A., 1994.

9 Leibniz, Noveaux Easis. II, XXVII, 9. Tomado de FERRATER MORA, José. Concepto de persona en la filosofía, diccionario de filosofía. Editorial Suramericana-Buenos Aires, 1979, p. 2553.
} 
mal que un individuo o colectividad ocupa dentro de unas relaciones sociales; es decir, que en el derecho romano se le brindaba protección a los actores de la vida social y jurídica, únicos titulares como sujetos de derechos ${ }^{10}$; eran personas solo los ciudadanos romanos que se contraponían a los extranjeros y a los esclavos que no podían ser personas jurídicamente; para serlo, deberían reunir tres requisitos: ser libre, ser romano extranjero y ser independiente de la patria potestad.

Desaparecida la sociedad estamental, por aplicación del principio de igualdad proclamado por la Revolución Francesa, la noción jurídica de "persona" se construye sobre la base de la filosofía en concepciones como la de Leibniz (racionalista) Fichte, Scheler, Kant ${ }^{11}$ (personalista, definió la persona como un fin en sí mismo), Hegel (idealista), Mounier (Personalismo ontológico), Kelsen (quien define al hombre como noción biológica antropológica y psicológica y no como noción jurídica que expresa una función específica del derecho ${ }^{12}$ ). Poco a poco la concepción dogmática apunta básicamente a la explicación técnica de la categoría conceptual llamada "Derechos subjetivos"; estos precisan de un titular, un sujeto, y este sujeto es el que recibe el nombre de "persona". Se trata ya de una categoría conceptual propiamente jurídica, pero de alcance más bien instrumental o técnico; en esta etapa, el punto de inflexión para reconocer o no la personalidad (subjetividad) tiene que ver con los derechos patrimoniales (únicos los que se les considera propiamente derechos) y con la noción de capacidad: o sea la aptitud para adquirirlos. En este contexto se va consolidando poco a poco la "teoría de la persona jurídica" como atribución de capacidad independiente a una entidad colectiva en todo parangonable a la persona natural. No se ve en esta etapa ningún inconveniente en considerar que la personalidad se inicia con el nacimiento, hecho visible y cierto que permite consolidar las adquisiciones patrimoniales y a su vez puede terminar con un sucesor legal: la institución de la muerte civil. La concepción de persona como noción técnico-legal llega a su máxima expresión con el normativismo Kelseniano, para quien el término no designa más que un centro de imputación normativa, donde la manualistica civil tradicional hoy, suele estar anclada en esta concepción formalista de "persona".

Esta segunda etapa da lugar a la tercera: etapa jurídico-valorica o institucional, de la cual se desprende un concepto de persona desarrollado desde el ámbito constitucional e internacional y cuya influencia produce una reinterpretación de las normas del Código Civil, tratando de superar los modelos positivistas - utilitaristas (P. Singer), consecuencialistas, contractualistas (Warnock, Engelharth), neoutilitarista (inspirados en Stuart y Bertham), principialistas (Childress Beauchamp), Empiristas - Racionalistas (Hume, Hobbes), para quienes el concepto de persona tiene un denominador común: los seres humanos se clasifican y valen según su categoría, donde la verdadera persona es aquel que tiene autoconciencia, autocontrol, sentido del futuro, capacidad para relacionarse con otros, comunicación, siendo estos los verdaderos indicadores de humanidad ${ }^{13}$.

Se observa que el Derecho no tiene sentido si pretende autojustificarse y que requiere de nociones no solo éticas, sino bioéticas fundamentales, sobre las cuales construirse 0 modificarse un derecho con sentido humano - espiritual, donde el ser humano es un fin en sí mismo y no un medio ${ }^{14}$. El concepto técnico de "persona" como sujeto de derechos y no como "objeto de derechos" adquiere un significado que varia de acuerdo a cada país, convirtiéndose la perso-

10 Recasens Sichez, Luis. Vida Humana y Sociedad y Derecho. Fondo de Cultura Económica. México, 1940, p. 262.

11 Concepto de persona en la Filosofía. En:

http://www.mercaba.org/ARTICULOS/E/el_concepto_de_persona_en_la_filosofia.htm. Fecha de consulta febrero 21 del 2015.

12 Corral Talciani, Hernán. El concepto jurídico de persona y su relevancia para la protección del derecho a la vida. Revista lus et Praxis, Universidad de Talca, Chile, 2005, volumen II (1): 37-53.

13 Ibíd. Corral Talciani, Hernán.

14 Spaeman, Robert," ¿Son todos los hombres personas? En Cuadernos de Bioética: El comienzo de la vida humana: Ética Biología y Derecho .ISSN 1132-1989, volumen 8, No.31, 3.trimestre julio -septiembre, 1997, págs. $1027-1033$. 
na en un centro de fundamentación y de desarrollo de todo el derecho.

La tradición jurídica colombiana consagra el concepto de persona como una dimensión jurídica del ser humano nacido vivo, donde el nacimiento y la muerte son los parámetros indiscutibles de iniciación y terminación de la existencia de las personas físicas, las cuales determinan la personalidad del ser humano, lo que indica que hay desprotección jurídica en el ordenamiento colombiano para el nasciturus ${ }^{15}$ quien no es titular de derechos $y$ deberes, negándosele absolutamente toda posibilidad de la personalidad legal.

Esta negación y contradicción de algunos artículos, resultan del análisis sistemático, no solo del Código Civil Colombiano, sino del Código Penal en contraposición con la Constitución Política de Colombia, la Jurisprudencia y el Derecho Comparado, en las que se evidencia la realidad jurídica del nasciturus y que a continuación describiré exponiendo las razones que deben tenerse en cuenta para que el concepto de persona sea replanteado.

\section{Aspecto normativo}

\subsection{Código CiviL}

Los artículos 33, 74, 90 y 93 establecen la definición de persona en los siguientes términos:
Artículo 90: “La existencia legal de toda persona principia al nacer, esto es, al separarse completamente de su madre. La criatura que muere en el vientre materno, o que perece antes de estar completamente separada de su madre, o que no haya sobrevivido a la separación un momento siquiera, se reputara no haber existido jamás". Dicho artículo, somete el derecho a la personalidad del nasciturus a una condición suspensiva: Sobrevivir a la separación completa de la madre lo cual significa que desde el momento del nacimiento el hombre es persona, tiene personalidad jurídica, tiene un estado civil como atributo de la personalidad.

Artículo 93: "Los derechos que se diferirían a la criatura que está en el vientre materno, si hubiese nacido y viviese, estarán suspensos hasta que el nacimiento se efectúe. Y si el nacimiento constituye un principio de existencia, entrara el recién nacido en el goce de dichos derechos, como si hubiese existido al tiempo en que se defirieron. En el caso del inciso del artículo 90 pasaran estos derechos a otras personas, como si la criatura no hubiese jamás existido". En este caso, la norma en comento, le reconoce al nasciturus sus derechos patrimoniales so- metidos a una condición: nacer vivo , ello obedece a razones morales, de justicia y políticas acordes con ideas y costumbres justados a un momento histórico" ${ }^{16 " ;}$ el Artículo 33 C.C. establece: "la palabra hombre, persona se aplican al individuo de la especie humana", y el artículo 74 C.C. define que «son personas todos los individuos de la especie humana, cualquiera que sea su edad, sexo, estirpe o condición».

A simple vista, existe una contradicción entre lo consagrado en los Artículos 90, 93 y los Artículos 33 y 74 del Código Civil Colombiano, toda vez que los primeros establecen la existencia de la persona al nacer viva, mientras que los segundos definen a la persona como sinónimo de hombre en su significado genérico que lo identifica como: "todo individuo de la especie humana". Y, si se considera que la concepción, entendida como la fecundación de un óvulo por el espermatozoide in situ o por fertilización in vitro, no genera ningún otro ser que no sea el ser humano, puede colegirse que se es persona desde la fecundación o fertilización según el Artículo 74 C.C.

Como puede inferirse, el concepto de hombre como ser humano es definido por la ciencia de la naturaleza como realidad natural o científica, y el concepto de persona

\footnotetext{
15 La gran mayoría de los textos en Derecho Civil, datan del siglo XIX y tal vez sea esta la razón por la cual frente al nasciturus, el ordenamiento jurídico colombiano utiliza expresiones como el "concebido", "el que esta por nacer" y el "que llegará a existir".

16 Tafur González, Álvaro. Código Civil colombiano. Bogotá, editorial Leyer, vigesimoquinta edición, ISBN 978-958-711217-7.Comentado. p. 36, 37,46.
} 
es elaborado por las ciencias del Derecho, indicando con ello que, el contenido de las normas no se relaciona con la persona, sino solamente con los actos de conducta humana, entendiéndose que decir de un hombre "es persona", significa que algunas de sus acciones $u$ omisiones constituyen el contenido de normas jurídicas, las que resultan inoperantes, contradictorias, deficientes frente a prácticas de rutina que se realizan en laboratorios de investigación y clínicas de fertilización, al considerarse que es la fecundación in vitro la que ha contribuido a dejar en evidencia la genética; para ésta, ningún embrión puede volverse específicamente humano, sino lo era desde el principio, afirmación que impulsa el renacimiento del debate sobre el comienzo de la vida y el concepto de persona, ya que este permanecía reservado al ámbito de la teoría,desde la noción clásica de persona como "substancia individual de naturaleza racional" y de la teoría legal de persona, por cuanto en el ordenamiento colombiano, es el nacimiento el que determina la existencia legal del nasciturus con una condición: que nazca vivo y con vida autónoma desde la separación completa de la madre, es decir, la existencia humana se define por el nacimiento y no por la concepción.

Al respecto, la vida humana - existencia humana - no se puede definir por su criterio estático, ni se puede afirmar que la vida comienza con el nacimiento como lo expresa de manera errónea el Artículo 90 CC, al no poderse hablar de muerte cuando no preexiste el ser y la vida, porque esta existe desde la concepción (fecundación) y no desde el momento del nacimiento, al ser esta una fase posterior a la existencia humana. Por esta razón, el Código Civil, en el Artículo 91 protege la vida del concebido y no nacido, puesto que la vida humana y la existencia comienzan científicamente desde la concepción, sin que ello represente confundir el nacimiento con la existencia, por ser dos conceptos que corresponden a momentos distintos del mismo proceso de desarrollo vital del ser humano ${ }^{17}$.

Por tales razones, es claro que la existencia humana se presenta desde la concepción, ya que la vida del nasciturus está en acto de ser, no en potencia, es vida animada que continua el proceso del libre desarrollo de la personalidad hasta el momento del nacimiento. Por ello, la legislación colombiana no puede separar la existencia biológica de la existencia jurídica de la persona, porque la vida es una única realidad biológica, jurídica y dinámica, anterior y superior a la existencia del Estado; es anterior al nacimiento y no como lo argumenta el Código Civil colombiano en su artículo 91, no pudiendo separarse la existencia biológica de la jurídica, por tratarse de una misma persona y una única realidad humana individual, porque la vida desde que comienza es un ciclo continuo hasta la muerte ${ }^{18}$.

Lo anterior significa que el reconocimiento de los derechos humanos y los derechos del nasciturus no admiten gradualidades ni condicionamientos, porque si estos derechos se predican de "todos los seres humanos", el criterio para su reconocimiento debe ser objetivo: "la pertenencia del individuo a la especie humana", consagrado en la Constitución Política como principio y derecho del respecto a la dignidad humana (Artículos 1, 2, 5, 11, 43 y 44) Por lo tanto, dicha Constitución, más exactamente el Artículo 42 inciso 6, al establecer que los hijos "procreados naturalmente o con asistencia científica tienen iguales derechos y deberes" no es extraña al momento de la procreación, que sería el de la "concepción", (término jurídico) o fecundación (término científico), coincidiendo en su interpretación, la existencia biológica con el comienzo de la existencia de la personalidad jurídica,sin importar que la fecundación se produzca in vivo o in vitro.

El nasciturus goza de protección constitucional e internacional mediante la ratificación de tratados de derechos humanos que, de conformidad con el Artículo 93 constitucional, forman parte del bloque de constitucionalidad tales como la Convención Americana de Derechos Humanos,

17 Gómez Tamayo, Daniel Fernando. La vida como fuente primigenia de los derechos humanos. Estudio argumentativo de la Sentencia C-355 de 2006.Corte Constitucional Colombia.Univeritas.cic.41.enero,2008, págs.16,17,18.En:Works. bepress.com/cgi/viewcontent.cgi?article=1003\&context=gomeztamayo. Fecha consulta febrero 21 de 2015.

18 Ibíd. Gómez Tamayo, Daniel Fernando. 
con la tradición jurídica latinoamericana. Para efectos de esta convención, persona es todo ser humano (Artículo 1.2); la convención sigue los lineamientos de la Declaración Americana de los Derechos y Deberes del hombre (Artículo 4 No. 1), el cual establece que el nasciturus, por su condición humana, también es jurídicamente persona ${ }^{19}$. Igualmente, en la Convención de los Derechos del Niño, entre muchas otras. De conformidad con los artículos 42 y 44 de la Constitución Política colombiana, los niños son titulares del derecho a la vida, y, si niño -según la Convención de los Derechos del Niño, es todo ser humano menor de dieciocho años, este entonces es titular del derecho a la vida.

Aceptada la tesis de que el nasciturus es un ser humano, debe admitirse que constitucionalmente tiene derecho a la vida, y si los Derechos Humanos se predican de los seres humanos, todo ser humano es titular del derecho a la vida, sea considerado o no por la legislación civil como persona.

El art. 90 del C.C y la postura jurisprudencial de la Corte Constitucional Colombiana según C-355 de 2006, es equivocada en sus argumentos donde "ser persona" se convierte en una propiedad del individuo de la especie humana que aparece solo a partir de un cierto intervalo de tiempo, como si el embrión fuera solo potencialmen- te una persona o una persona potencial, cuando en realidad es una persona humana en acto y no en potencia de ser persona, porque ese nuevo ser está siendo y existiendo "per se" conforme a su dignidad ontológica desde el mismo momento de la concepción hasta el momento de su muerte, según Daniel Fernando Gómez Tamayo, experto constitucionalista y par académico de Colciencias; para la Corte, el nasciturus no es persona, no es agente moral ${ }^{20}$; dicha Corte se extralimitó en sus funciones imponiendo con su veredicto una interpretación ideológica de la Constitución Política, no solo con su decisión (despenalizar el aborto en tres situaciones específicas) condenó normas vigentes del derecho penal originadas en el constituyente colombiano, sino que impuso nuevas interpretaciones de toda la tradición legislativa y algunas normas internacionales $e$ incluso de su propia jurisprudencia al desconocer otras jurisprudencias como la C-013/97, C-133/94, T102/93, T-452/93, las cuales manifiestan que la Constitución protege la vida como valor y derecho primordial insustituible del cual es titular todo ser humano desde el principio hasta el final de su existencia física, por lo tanto se protegen sus derechos en todos sus estadios.

Queda claro que, para la Corte, según sentencia de aborto, el nasciturus no es persona. Por ello, no es sujeto de derechos como lo es el ya nacido, aunque su vida tiene protección constitucional, mas no como derecho fundamental a la vida del nasciturus; por lo que si no existe un derecho fundamental a la vida del nasciturus, no puede hablarse de ningún otro derecho fundamental del no nacido (en palabras de Mónica Roa, demandante, al darle interpretación a la Sentencia 355 de 2006), es decir, no es titular de derechos, dándosele implícitamente el tratamiento de cosa, mera potencia o expectativa de vida ${ }^{21}$.

Como resultado de lo anterior, se nota marcadamente cómo en Colombia no hay garantías suficientes para acceder a un debate democrático fundamentado en críticas razonadas sin interpretaciones utilitaristas, con una única ideología política, sin libertad de elegir otras interpretaciones, convirtiéndose en una especie de tiranía silenciosa que margina a quienes contradicen el verdadero espíritu de la Constitución Política, los derechos humanos, las interpretaciones bioéticas, personalistas entre otros, ignorando deliberadamente los avances de la ciencia, dejando al arbitrio de una minoría decisiones que tienen que ver con el ser humano hoy tan desprotegido como lo es el nascitirus, al decidir sin consenso político o claridad expresa en la Constitución, llevándolos a posturas equivocadas, no siendo la Corte

19 Persona y bioética. Universidad de la Sábana (2006). ISSN (Versión imprenta): 0123-3122. Colombia. Vol. 10 No. 026. p. 103.

20 Balcázar G., Andrés. Universidad del Rosario. La despenalización del aborto. Escuela de Ciencias Humanas. Junio 2010, p. 61.

21 Ibíd. . Balcázar G. Andrés. págs. 19, 27, 30, 37, 38, 39, 47, 52, 54, 56, 58, 60. 
el órgano legitimado para decidir asuntos tan trascendentales como el valor de la vida y el concepto de persona, y mucho menos para negarle la posibilidad al nasciturus de ser persona.

El anterior recorrido histórico - legislativo, con sustento de las normas en mención y su consecuente explicación e interpretación, son algunas de las consideraciones que deben tenerse en cuenta para la modificación de los artículos que se relacionan con el estatus jurídico de las personas y el concepto de persona en Colombia, sustentado en argumentos razonables y no racionales, con una mejor interpretación, y un razonado equilibrio de valores morales, espirituales, antropológicos, y biológicos basados en posturas más personalistas que utilitaristas, donde exista una línea de pensamiento uniforme ajustado a los postulados bioéticos de corte personalista, quienes le dan al nasciturus el status de persona a salvo de toda consideración utilitarista, sin separarlo de su condición de humanidad, con derecho a la vida, a su desarrollo, a la identidad, a la no discriminación, derechos estos inherentes a la persona.

\section{FundamentaCión PARA ATRI- bUIRLE al Nasciturus el Ca- RÁCTER DE PERSONA}

Los diferentes tratados internacionales sobre Derechos Humanos, la Constitución colombiana y su filosofía humanista propia de un estado social de derecho, han sido vitales como fuente interpretativa para atribuirle al nasciturus desde la concepción el carácter de persona como sujeto de derechos, sustentado en el principio ético que "todas las personas gozan de dignidad humana, lo que significa que la dignidad humana es inherente al embrión humano de conformidad con su origen, como principio del estatus esencial del nasciturus y en un plano de igualdad, consecuente con su personalidad jurídica". ${ }^{22}$

Esa personalidad es, por tanto, el elemento constitutivo de todos los seres humanos, no una cualidad suya, y desde luego en ningún caso, una cualidad adquirida gradualmente $^{23}$. Cuenta con una identidad genética propia, que es invariable desde la concepción hasta la muerte, pero es genéticamente distinto a otro ser humano, que al ser inmutable en su identidad genética, lo es del mismo modo en su esencia humana, y, en consecuencia, en su condición de persona, por cuanto cada individuo se hace acreedor de su dignidad y personalidad desde el momento en que se constituye su realidad biológica, es decir, desde la concepción y cuya identidad no varía a lo largo de la vida, teniendo el derecho la obligación de proteger adecuadamente a las personas $y$, en coherencia con el continuum de la naturaleza humana, esta protección debe aplicar desde la fusión de los gametos hasta la muerte natural. ${ }^{24}$

Un embrión biológicamente humano, es un individuo biológicamente hombre o mujer desde el primer momento de su existencia, al tenerse en cuenta que con el nacimiento no se da un salto de la animalidad a la humanidad. Estamos ante un ser potencialmente orientado a desarrollarse y a devenir en una niña o niño ${ }^{25}$, por cuanto las distintas fases de su desarrollo morfológico constituyen un continuo, gradual y único proceso, no existiendo por tanto un salto cualitativo que interrumpa de modo radical su proceso de formación ${ }^{26}$, con individualidad y unicidad genética y con una única diferencia: que el nasciturus está dentro del útero y el recién nacido esta fuera de él.

Dichas cualidades son suficientes para el reconocimiento de su personalidad y el establecimiento de sus derechos, los cuales están ligados a su condición de ser humano digno de protección y seguridad

22 Knoepffler, Nikolaus Joannes.La dignidad humana en Bioética: Hacia un concepto normativo del embrión.1.Auflage. Berlin: Springer, 2004, ISBN-3-540-21455-0, ps.27, 53 .En http://www.fundacionmhm.org/pdf7mono4/Articulos/articulo6.pdf.Consultado en febrero del 2015.

23 Spaemann, Robert, op.cit. pgs. 1027-1033.

24 Jouve de la Barreda, Nicolás. La genética y la dignidad del ser humano. Cuadernos de Bioetica.xxiv.2013/1. pgs.98,99,100. En: htpp://www.aebioetica.org/revista/2013/24/80/91.pdf.Fecha de consulta febrero de 2015.

25 Andorno, Roberto. Dimensión biológica de la personalidad humana, debate sobre el estatuto del embrión.1. El cuerpo humano del embrión. Cuadernos de Bioética ISSN 1132-1989, vol.15, No 53, 2004, pgs.30, 31.

26 Ibíd. Andorno, Roberto, p. 32. 
jurídica, independientemente del desarrollo de cada una de las etapas del embrión y del reconocimiento de su personalidad jurídica recién a partir de su nacimiento como ocurre en Colombia, a partir de la Sentencia C-355 de 2006 sobre despenalización parcial del aborto.

\section{ConcLusiones}

En general, la imputación de derechos patrimoniales a favor del nasciturus está sometida a la condición suspensiva de la existencia legal, y por ende a la personalidad; lo cual indica que solo una vez cumplida la condición de existencia legal, el derecho correspondiente se difiere en cabeza del nacido vivo. Igualmente, el derecho a la personalidad está sometido a la misma condición suspensiva, es decir, que sus derechos en la legislación colombiana son meras expectativas y por ello el ordenamiento civil colombiano de manera expresa le asigna un curador de bienes a los derechos eventuales del que está por nacer (Artículo 433); existen igualmente artículos del Código Civil como el $1019,1014,874$, los cuales se refieren a la imputación de derechos a personas inexistentes, siendo esta la misma constante del Artículo 90 C.C: que las personas existan en un tiempo. Así que cualquier derecho vale hasta después del nacimiento, condición esta para ser persona, desdibujándose con ello el verdadero concepto de persona y la dignidad del nasciturus, al considerársele persona solo después del nacimiento vivo.

Todo ser humano, desde el momento de la fecundación, es persona en sentido jurídico, ya que no se puede separar la existencia legal de la existencia biológica como lo hace erróneamente el Código Civil colombiano, pues se trata de una misma y única realidad existencial biológica que el mismo ordenamiento jurídico colombiano no puede desconocer y menos puede ir en contra de los avances de la ciencia y de los mismos conceptos científicos; al contrario, el Derecho debe ir a la par con los avances de la ciencia y, el Estado no puede apoderarse jurídicamente de un derecho que se adquiere con la fecundación, por el solo hecho de la condición de SER HUMANO y la DIGNIDAD INTRINSECA que tiene el concebido.

La persona no debe definirse por la capacidad de ejercicio; la persona natural es persona jurídica y esta se define por el criterio de la capacidad de goce de esa especial dignidad y no por la simple capacidad de ejercicio. Por ello, se dice desde el punto de vista tomista que persona es todo sujeto de derechos y obligaciones, y no un sujeto capaz de ejercer los derechos y de contraer obligaciones, ya que hay muchos menores incluso discapacitados, comatosos, especiales, que no pueden ejercer ciertos derechos de por sí y no por ello dejan de ser persona.

La inconsistencia de algunas de las normas del Código $\mathrm{Ci}$ vil, denotan claramente la falta de criterios razonados y el desconocimiento y falta de argumentos científicos, bioéticos, cristianos, que marcan la existencia de un derecho rezagado y obsoleto que no va a la par con los avances de la ciencia; por lo tanto, existen fuertes razones para atribuirle el respeto y calidad de persona al nasciturus y su concreción depende de la obra de todos nosotros según en la esfera en que se esté: familia, colegio, universidad, política, hospital, teniendo como motor principal la fe en Dios.

La genética es clara al afirmar que la vida comienza en el momento mismo de la fecundación, concepto este frecuentemente ignorado o mal interpretado en las discusiones de las que dependen decisiones éticas, o a su vez discusiones sobre el concepto de persona, de las que depende el tratamiento que se le de al nasciturus, llámese moriturus, embrión, pre embrión. Ejemplo de ello es la experimentación con embriones, el trato discriminado con los embriones sobrantes en técnicas de fertilización, el aborto y, mas aún, en un accidente de tránsito, probada la responsabilidad de un conductor donde se produce la muerte de mujer en embarazo, se condena al responsable por la muerte de una persona y no de dos en el caso del nasciturus. Por lo tanto, el hecho que el embrión no sea un yo consciente, no es un argumento para dejarle de atribuir la misma individualidad preconsciente que conviene al organismo humano, sobre todo al probarse que el desarrollo de una etapa a otra es continuo y gradual; y que con el nacimiento no hay un origen sino una continuidad en el ser de la persona, ya que la vida es un proceso que se inicia con la concepción y termina con la muerte. 